\title{
Engineering
}

\section{Finite element analysis of implant-supported prosthesis with pontic and cantilever in the posterior maxilla}

Victor Eduardo de Souza Batista, Fellippo Ramos Verri, Daniel Augusto de Faria Almeida, Joel Ferreira Santiago Junior, Cleidiel Aparecido Araújo Lemos \& Eduardo Piza Pellizzer

To cite this article: Victor Eduardo de Souza Batista, Fellippo Ramos Verri, Daniel Augusto de Faria Almeida, Joel Ferreira Santiago Junior, Cleidiel Aparecido Araújo Lemos \& Eduardo Piza Pellizzer (2017) Finite element analysis of implant-supported prosthesis with pontic and cantilever in the posterior maxilla, Computer Methods in Biomechanics and Biomedical Engineering, 20:6, 663-670, DOI: 10.1080/10255842.2017.1287905

To link to this article: https://doi.org/10.1080/10255842.2017.1287905

Published online: 13 Feb 2017.

Submit your article to this journal $\pi$

Џll Article views: 310

View Crossmark data

Citing articles: 4 View citing articles $\llbracket \nearrow$ 


\title{
Finite element analysis of implant-supported prosthesis with pontic and cantilever in the posterior maxilla
}

\author{
Victor Eduardo de Souza Batista a , Fellippo Ramos Verrib, Daniel Augusto de Faria Almeidac, \\ Joel Ferreira Santiago Junior ${ }^{d}$, Cleidiel Aparecido Araújo Lemos ${ }^{\mathrm{a}}$ and Eduardo Piza Pellizzer ${ }^{\mathrm{e}}$
}

${ }^{a}$ Graduate Program in Dentistry, Department of Dental Materials and Prosthodontics, Araçatuba Dental School, UNESP - Univ Estadual Paulista, Araçatuba, Brazil; 'b Department of Dental Materials and Prosthodontics, Araçatuba Dental School, UNESP - Univ Estadual Paulista, Araçatuba, Brazil; 'SSchool of Dentistry, Federal University of Alfenas - UNIFAL-MG, Alfenas, Brazil; 'Department of Health Sciences, University of Sacred Heart USC, Bauru, Brazil; ' Department of Dental Materials and Prosthodontics, Araçatuba Dental School, UNESP - Univ Estadual Paulista, Araçatuba, Brazil

\begin{abstract}
The aim of this study was to evaluate the influence of pontic and cantilever designs (mesial and distal) on 3-unit implant-retained prosthesis at maxillary posterior region verifying stress and strain distributions on bone tissue (cortical and trabecular bones) and stress distribution in abutments, implants and fixation screws, under axial and oblique loadings, by 3D finite element analysis. Each model was composed of a bone block presenting right first premolar to the first molar, with three or two external hexagon implants $(4.0 \times 10 \mathrm{~mm})$, supporting a 3-unit splinted dental fixed dental prosthesis with the variations: M1 - three implants supporting splinted crowns; M2 - two implants supporting prosthesis with central pontic; M3 - two implants supporting prosthesis with mesial cantilever; M4 - two implants supporting prosthesis with distal cantilever. The applied forces were $400 \mathrm{~N}$ axial and $200 \mathrm{~N}$ oblique. The von Mises criteria was used to evaluate abutments, implants and fixation screws and maximum principal stress and microstrain criteria were used to evaluate the bone tissue. The decrease of the number of implants caused an unfavorable biomechanical behavior for all structures (M2, M3, M4). For two implant-supported prostheses, the use of the central pontic (M2) showed stress and strain distributions more favorable in the analyzed structures. The use of cantilever showed unfavorable biomechanical behavior (M3 and M4), mainly for distal cantilever (M4). The use of three implants presented lower values of stress and strain on the analyzed structures. Among two implant-supported prostheses, prostheses with cantilever showed unfavorable biomechanical behavior in the analyzed structures, especially for distal cantilever.
\end{abstract}

\section{ARTICLE HISTORY}

Received 10 August 2016 Accepted 24 January 2017

\section{KEYWORDS}

Finite element analysis; dental implant; biomechanical phenomena

\section{Introduction}

The quality of life of edentulous patients has increased due to the use of dental implants (Pennington \& Parker 2012). Nowadays, high success rates are reported for this therapy with follow-up studies showing the efficacy among different connection types and implant geometries over years (Lemos et al. 2016). However, biomechanical factors may influence this longevity (Fu et al. 2012), such as quality or quantity of bone tissue (Goiato et al. 2014), splinting of crowns (Pellizzer et al. 2015), stress distribution generated by occlusion and masticatory force, number of implants and implant location (Chen et al. 2012). In this context, the literature has associated a greater tendency to failure in dental implants placed in the maxillary posterior region due to lower bone density (Goiato et al. 2014).
The bone resorption after tooth loss may interfere the optimal positioning of the implant and, sometimes, the resorption may preclude the number adequate of implants (Milinkovic \& Cordaro 2014). In this situation, the use of pontic or cantilever (mesial or distal) is suggested as an alternative, in order to avoid surgical procedures that generate more time for the treatment as well as an increase in cost and surgical morbidity (Harder et al. 2011). Nonetheless, the longevity of these treatments still not fully understood. Moreover, unfortunately, some clinicians tend to indicate implant number reduction based only in the decrease of treatment costs without background in biomechanical concepts, since there is insufficient scientific evidence to guide the practitioner as to how many dental implants are necessary to rehabilitate 
the patient when multiple teeth are missing in posterior quadrants.

The finite element analysis is usually used to assess the biomechanical behavior of situations that involve osseointegrated implants (Torcato et al. 2014; Verri et al. 2016, 2017). Furthermore, the results of these studies have already been indicated for improving the biomechanical understanding of several materials or situations used in dentistry and could have their results carefully extrapolated to daily clinical (Van Staden et al. 2006).

In order to increase the knowledge about the topic, since the literature is scarce of studies that assess the effect of pontic and cantilever to rehabilitate the posterior maxilla, the aim of this study was to evaluate the influence of pontic and cantilever designs (mesial and distal) on 3-element implant-retained prosthesis placed at maxillary posterior region, verifying stress and strain distributions on bone tissue (cortical and trabecular bones), and stress distribution in abutments, implants and fixation screws, under axial and oblique loadings, by 3D finite element analysis. The study hypotheses were: (1) the reduction of the number of implants would provide an unfavorable biomechanical behavior; (2) the pontic and cantilever would generate difference in the biomechanical behavior in the analyzed structures.

\section{Material and methods}

\section{Experimental design}

Four models were developed with three variation factors: the number of implants (three or two), design of rehabilitation (3-unit implant-supported prosthesis over three implants or over two implants varying among central pontic, mesial cantilever and distal cantilever) and loading type (axial and oblique).

\section{Three-dimensional FE modeling}

The model configurations are summarized in the Table 1. Each model was composed of a bone block comprising from the first premolar to first molar, with three or two implants of external hexagon $(\mathrm{EH})$ of $4.0 \times 10 \mathrm{~mm}$ (Conexao Sistemas de Protese Ltda., Aruja, Sao Paulo,
Brazil), with a screw-retained implant-supported 3-unit prosthesis.

The design of bone block was composed of trabecular bone in the center surrounded by $1 \mathrm{~mm}$ of cortical bone layer, simulating bone type IV (Lekholm \& Zarb 1985). Bone tissue was obtained based on previous studies (Torcato et al. 2014; Ramos Verri et al. 2015), in which the data of computerized tomography were used for 3D modeling (InVesalius software, CTI, Campinas, São Paulo, Brazil), and realized further surface simplification with Rhinoceros 4.0 software (NURBS Modeling for Windows, Seattle, Washington, USA).

The implant design was obtained by simplifying of a computer-aided design (CAD) of EH implant. Placement of the implants for the model with three implants was simulated with a distance of $7 \mathrm{~mm}$ between the premolars, measured from center to center of implants, and distance of $8.75 \mathrm{~mm}$ between the second premolar and first molar (Puri et al. 2007). In the model with central pontic the implant of second premolar was removed and the other positions were maintained. For simulation of mesial cantilever, the implant positioned in the first premolar was removed and, finally, for the rehabilitation with distal cantilever, the implant positioned in the first molar was removed. Furthermore, the mesiodistal distance and the design of the prosthesis were kept the same for all. The simulation of prosthetic abutment UCLA (Universal Castable Long Abutment) was the same for all situations. Both metal-ceramics prostheses were simulated in the straight line and splinted.

Similarly, the simplification of the implants, abutments, crowns and fixation screws were performed using the SolidWorks 2010 (SolidWorks Corp., Waltham, Massachusetts, USA) and Rhinoceros 4.0 software, and the simplifications this were the same for all models (Figure 1). Lastly, all geometries were exported to discretization to finite element software (FEMAP 11.1.2, Siemens PLM Software Inc., Santa Ana, California, USA).

\section{D analysis configuration}

The FEMAP 11.1.2 software was used for pre- and post-processing phases. In the pre-processing stage were generated meshes with tetrahedral parabolic solid elements

Table 1. Description of models.

\begin{tabular}{|c|c|c|c|c|c|}
\hline Implant & Models & Number of Implants & Rehabilitation & Loads & Number of nodes / elements \\
\hline \multirow[t]{4}{*}{$\overline{\mathrm{EH}}(4.0 \times 10 \mathrm{~mm})$} & M1 & Three & Splinted crowns & $\begin{array}{l}\text { Axial } \\
\text { Oblique }\end{array}$ & $1,399,415 / 581,493$ \\
\hline & M2 & Two & Central pontic & $\begin{array}{l}\text { Axial } \\
\text { Oblique }\end{array}$ & $1,022,977 / 339,218$ \\
\hline & M3 & Two & Mesial cantilever & $\begin{array}{l}\text { Axial } \\
\text { Oblique }\end{array}$ & $1,058,045 / 363,069$ \\
\hline & M4 & Two & Distal Cantilever & $\begin{array}{l}\text { Axial } \\
\text { Oblique }\end{array}$ & $1,044,321 / 352,569$ \\
\hline
\end{tabular}




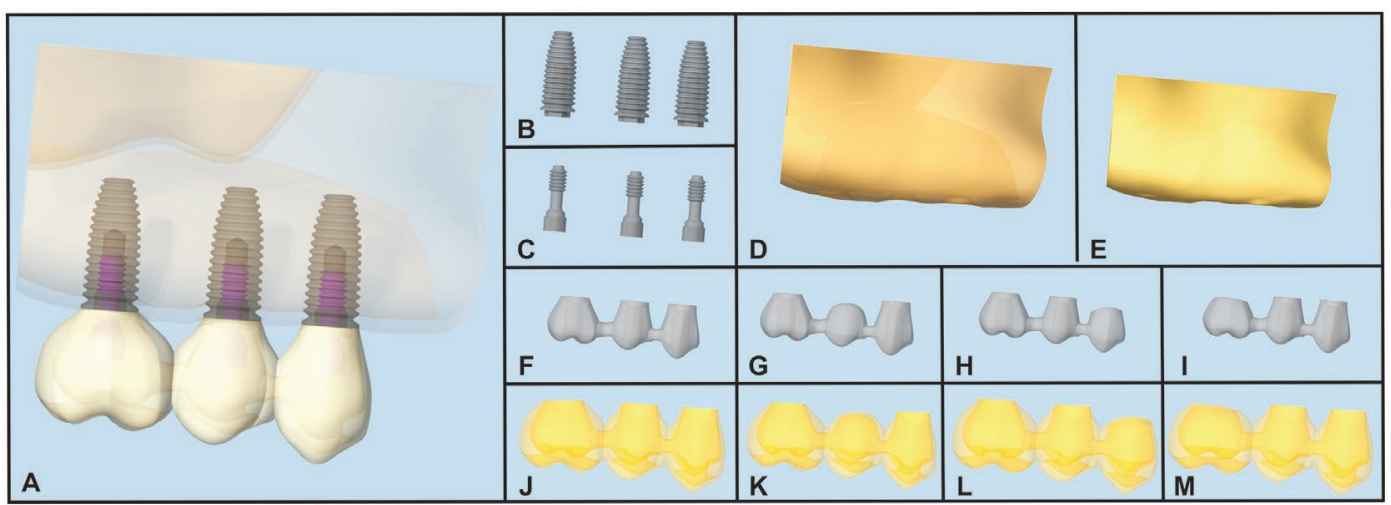

Figure 1. Three-dimensional Finite Element modeling. (A) example of the model (M1) after modeling, all models followed this quality of modeling. Solid modeling of: (B) implants; (C) fixation screws; (D) cortical bone; (E) trabecular bone; (F) metal framework of the M1; $(\mathrm{G})$ metal framework of the $\mathrm{M} 2 ;(\mathrm{H})$ metal framework of the $\mathrm{M} 3$; $(\mathrm{I})$ metal framework of the $\mathrm{M} 4$; $(\mathrm{J})$ veneering porcelain of the $\mathrm{M} 1$; $(\mathrm{K})$ veneering porcelain of the $M 2 ;(L)$ veneering porcelain of the $M 3 ;(M)$ veneering porcelain of the M4.

(see number of nodes and elements in the Table 1). Mechanical properties of each simulated material were attributed to the meshes using literature values (Sevimay et al. 2005; Torcato et al. 2014; Verri et al. 2014; Santiago et al. 2016) (Table 2). All materials were considered isotropic, homogeneous and linearly elastic (Verri et al. 2014; Santiago et al. 2016).

\section{Interfaces conditions, boundary and loads}

Symmetric welded contacts were simulated between crown/abutment, abutment/fixation screw, fixation screw/ implant, cortical bone/trabecular bone, implant/cortical bone and implant/trabecular bone interfaces, while symmetric contact was defined between the prosthetic component/implant to simulate clinical characteristic. The boundary conditions were established as fixed in all axes $(x, y$ and $z)$ in the upper surface of the bone block, simulating the fixation of the maxilla in the viscerocranium. The applied force was $400 \mathrm{~N}$ axially ( $50 \mathrm{~N}$ at each cusp tip), and $200 \mathrm{~N}$ obliquely (50 N applied at $45^{\circ}$ in each lingual cusp ridge of buccal cusp) (Figure 2).

\section{Finite element analysis}

All analyses were processed by NeiNastran 11.1 software (Noran Engineering, Inc., Westminster, CA, USA). The obtained results were transferred to software FEMAP 11.1.2 for graphical visualization of stress and strain maps. The von Mises criteria were used to evaluate abutments, implants, and fixation screws (Ramos Verri et al. 2015). The maximum principal stress and microstrain criteria were used for analysis of the bone tissue (Ramos Verri et al. 2015). The microstrain analysis $\left(\mu \varepsilon-\right.$ strain $\left.\times 10^{-6}\right)$ was used to evaluate the bone tissue (Ramos Verri et al.
Table 2. Mechanical properties applied in the finite element analysis.

\begin{tabular}{|c|c|c|c|}
\hline Structures & $\begin{array}{l}\text { Elastic modu- } \\
\text { lus (GPa) }\end{array}$ & $\begin{array}{c}\text { Poisson ratio } \\
\text { (v) }\end{array}$ & References \\
\hline $\begin{array}{l}\text { Trabecular bone } \\
\text { with low } \\
\text { density (type } \\
\text { bone IV) }\end{array}$ & 1.10 & 0.30 & $\begin{array}{l}\text { Sevimay et al. } \\
(2005)\end{array}$ \\
\hline Cortical bone & 13.7 & 0.30 & $\begin{array}{l}\text { Torcato et al. } \\
\text { (2014) }\end{array}$ \\
\hline Titanium & 110.0 & 0.35 & $\begin{array}{l}\text { Torcato et al. } \\
\text { (2014) }\end{array}$ \\
\hline $\mathrm{Ni}-\mathrm{Cr}$ alloy & 206.0 & 0.33 & $\begin{array}{l}\text { Verri et al. } \\
\text { (2014) }\end{array}$ \\
\hline $\begin{array}{c}\text { Feldspathic } \\
\text { porcelain }\end{array}$ & 82.8 & 0.35 & $\begin{array}{l}\text { Santiago et al. } \\
\text { (2016) }\end{array}$ \\
\hline
\end{tabular}

2015), in order to obtain values to compare with the risk scale of resorption provided by Frost (2003).

\section{Results}

\section{Crown, implant, prosthetic components and fixation screw - von Mises criteria}

Under axial loading, the decrease of the number of implants (M3 and M4) was unfavorable for stress distribution on these structures, mainly for the distal cantilever configuration (model M4) (Figure 3). The maximum von Mises stress values increased from 64.77 (M1) to 84.77 MPa (M2), 107.97 (M3) and 335.01 MPa (M4). The M1 presented higher stress concentration on distal wall of the implant and abutment of first molar; the M2 presented higher stress distributed on distal and mesial wall of the implant and abutment of first molar and on distal wall of the implant and abutment of first premolar; the M3 presented higher stress concentration on the mesial wall of the implant and abutment of the first premolar; and the M4 presented worst situation with higher stress 

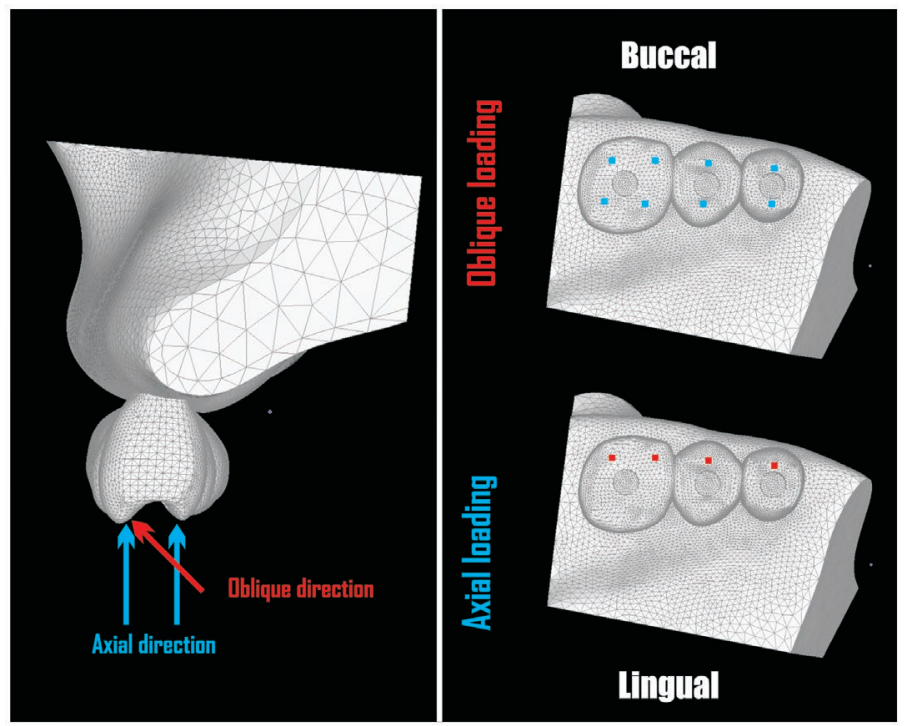

Figure 2. Scheme to explain the applied force. (A) Mesial view, arrows illustrating the applied force axially and obliquely; (B) Oclusal view, blue point illustrating the location of the applied force axially ( $50 \mathrm{~N}$ at each cusp tip), red point illustrating the location of the applied force obliquely ( $50 \mathrm{~N}$ applied at $45^{\circ}$ in each lingual cusp ridge of buccal cusp).

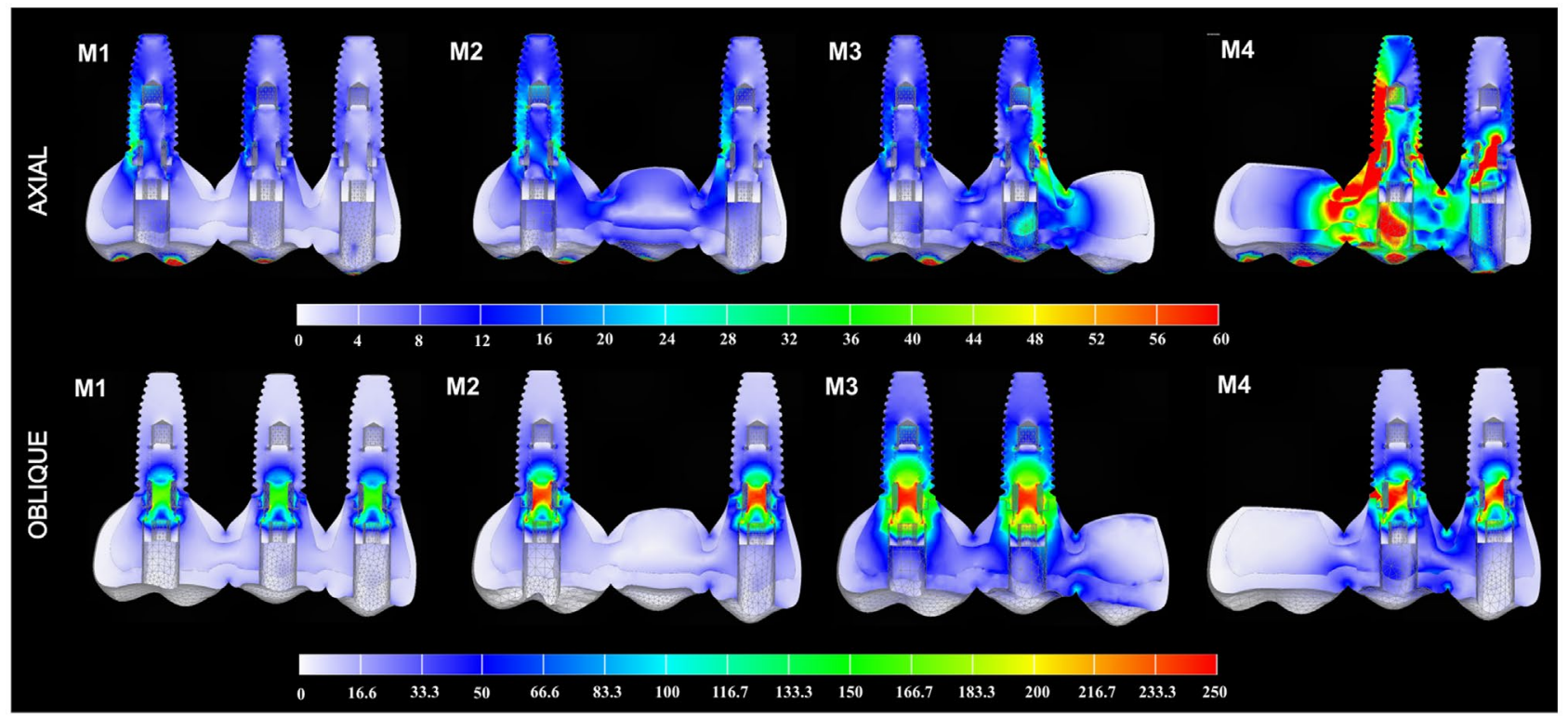

Figure 3. Stress distribution according to von Mises criteria: crown, implant, abutment and screw fixation. Axial and oblique loadings, buccal view. (M1) three implants with splinted crowns; (M2) two implant with pontic; (M3) two implant with mesial cantilever; (M4), two implants with distal cantilever. Values in MPa.

concentration on all over implant/crown set of the second premolar and in the fixation screw of the first premolar.

The oblique loading showed similar stress distribution between analyzed models with overloading on fixation screws. The stress concentration increased in the fixation screws for all models compared to M1 (Figure 3). Maximum von Mises stress values were 560.58, 770.50, 761.74 and $951.54 \mathrm{MPa}$ for M1, M2, M3 and M4, respectively. The M3 and M4 presented significant increase of stress concentrated in the abutments comparatively to other models.

\section{Bone tissue (cortical and trabecular bone) - maximum principal stress criteria}

Under axial loading, the stress concentrations were near from implant neck areas. The highest values of tensile and compressive stresses were localized in the cortical bone for 


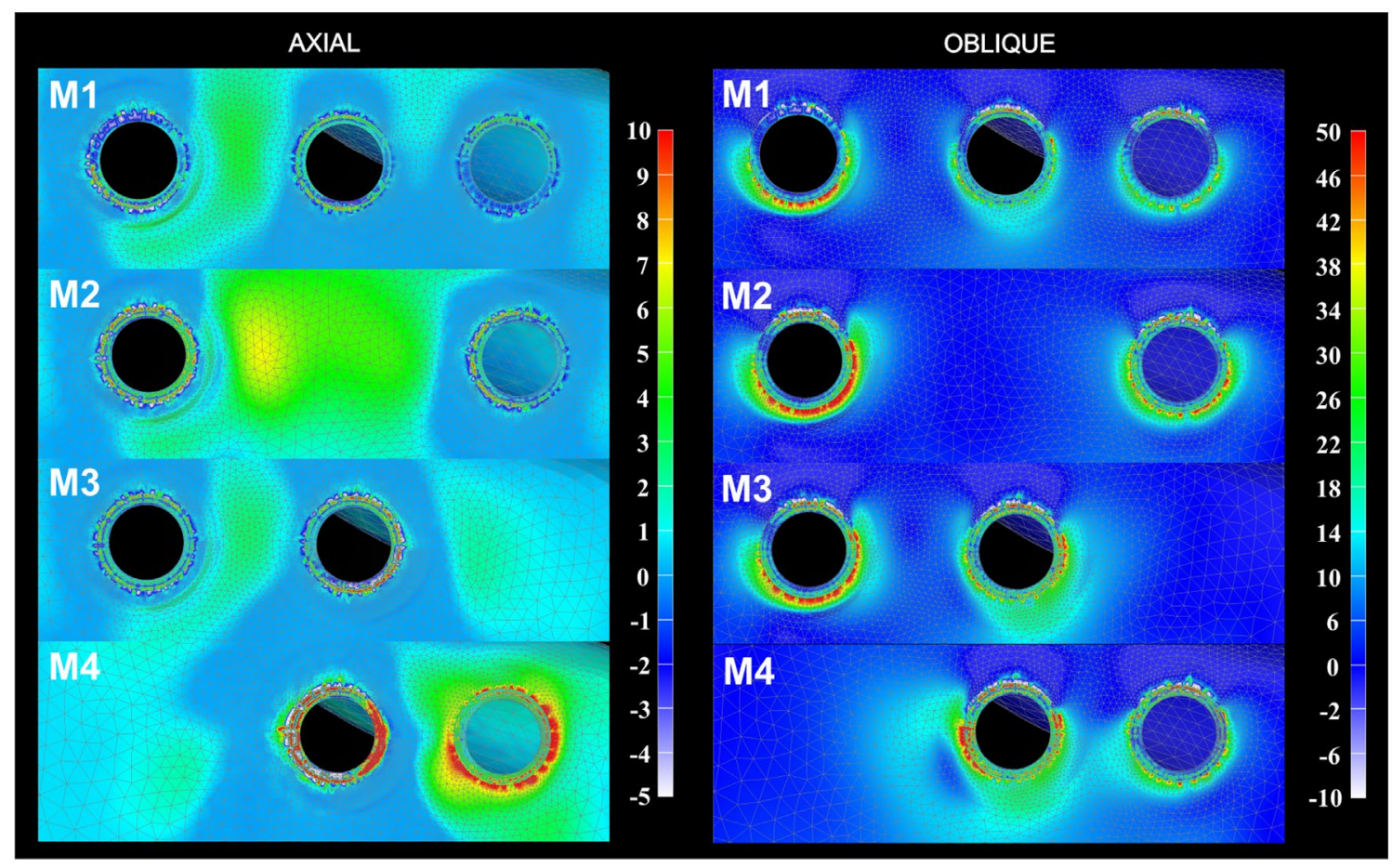

Figure 4. Maximum principal stress: cortical bone. Axial and oblique loadings, occlusal view. (M1) three implants with splinted crowns; (M2) two implant with pontic; (M3) two implant with mesial cantilever; (M4), two implants with distal cantilever. Values in MPa.

all models (Figure 4). The M1 showed the lowest concentration of compressive and tensile stress compared with other models. Among two implant-supported prostheses, the M2 dissipated the compressive and tensile stress in a similar way around the two implants, whereas the M3 showed compressive and tensile stress concentrated on bone around implant near from cantilever; the M4 showed considerably increase of compressive and tensile stress than other models.

Oblique loading lead to increase of compressive and tensile stress compared to axial loading, with concentration of tensile stress around implant neck areas in the lingual side and compressive stress in the same area but in the buccal side on cortical bone (Figure 4). The lowest compressive and tensile stress was observed around the implants of the M1 when compared with others models. The bone tissue around the most distal implant always presented the most overloaded area. Bone tissue around implant neck near from cantilever presented more extensive areas of stress concentration in the models with cantilever configurations.

\section{Bone tissue (cortical and trabecular bone) - microstrain criteria}

Under axial loading, the highest values of microstrain located on the cortical and trabecular bone around the implant neck and in apical area of trabecular bone of the all models (Figure 5). The M1 showed the lowest extensive area of microstrain around implant neck compared to other models in both bone tissues. The M2 presented more extensively area around distal implant neck (molar). The M3 and M4 presented this concentration area around the implant near from cantilever. Comparatively, the M4 presented higher values of microstrain reaching over than $3.000 \mu \varepsilon$.

The oblique loading increased the microstrain values for both bone tissues compared to axial loading (Figure 5). The M1 showed the lowest microstrain concentration and the M4 the highest concentration. The distribution was similar to the axial load but always concentrating more strain to the buccal side.

\section{Discussion}

The first hypothesis has been accepted since the reduction in the number of implants caused an increase of stress in the implant, prosthesis, fixation screws and bone tissue, as well as the second hypothesis, since the use of pontic caused a different biomechanical behavior in the structures when compared to models with cantilevers designs.

In the present study, the reduction of number implants caused an unfavorable biomechanical behavior for the analyzed structures, as described in previous studies (Akca \& Iplikcioglu 2002; Hasan et al. 2011; Chen et al. 2012; Alencar et al. 2015). Thus, the model with more 


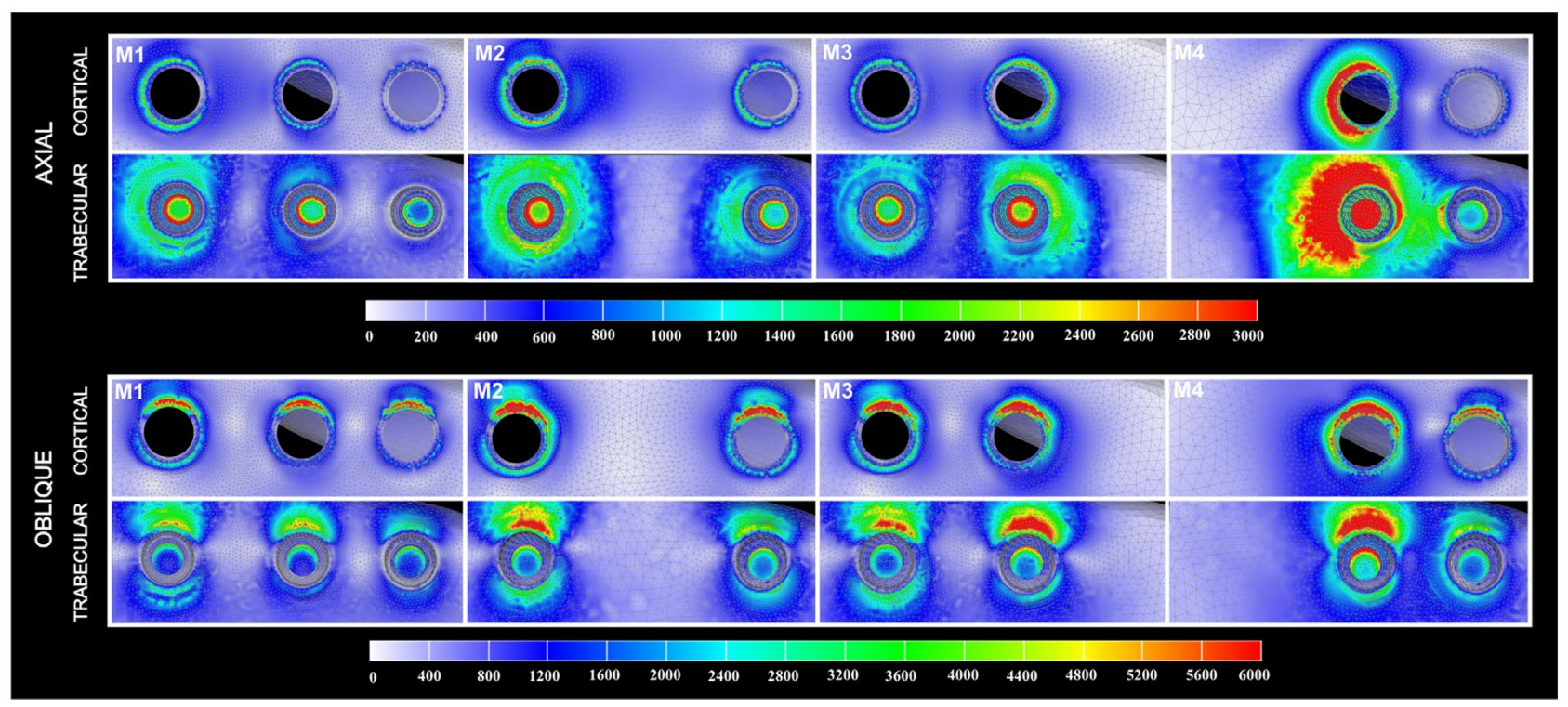

Figure 5. Microstrain: Cortical $(C)$ and trabecular $(T)$ bone analysis. Axial and oblique loadings, occlusal view. (M1) three implants with splinted crowns; (M2) two implant with pontic; (M3) two implant with mesial cantilever; (M4), two implants with distal cantilever.

number of implants was used as control group for this study. The use of pontic or cantilever can be an alternative for clinical situations where the use an ideal number of implants is not allowed due to bone resorption that does not allow the placement of other implants or even because the financial limitations. In this context, the use of pontic generated stress/microstrain distribution more favorable for the structures than models with cantilevers, corroborating with previous studies (Yokoyama et al. 2004; Sallam et al. 2012).

Moreover, distal cantilever was worse biomechanically than mesial cantilever. This fact is explained due to the size of occlusal table of first molar which is higher than occlusal table of the first premolar and due the number of the cusps of molar that receipt application of four loads against application of two loads in the first premolar. Anyway, these results corroborate with Kreissl et al. (2007) that reported that the use of implant-supported fixed partial dentures with cantilever had a higher incidence of complications in a prospective study. In fact, this study showed higher stress concentration mainly on the fixation screw of models with two implants and under oblique load even being this applied load half the axial force. Stress concentration in this area could lead to screw loosening and requiring more appointments to solve this discomfort or re-tightening or replacing the screw. Thereby, the use of treatment with distal cantilever should be avoided. In this situation, the use of bone graft and the placement of a dental implant is suggested to obtain treatment with more longevity.

The length of implants in this study was of $10 \mathrm{~mm}$ for all situations. However, this type of prosthetic planning may not be applied for all cases in the clinical routine. In this context, the clinician may use implant with different length accordingly bone availability in situation which is necessary the placement of 3 implants to support the replacement of missing premolars and molar. For this case, Pellizzer et al. (2015) suggests that the increasing of the implant length is a factor that could influence for biomechanical behavior of rehabilitation, mainly for the first premolar implant (Pellizzer et al. 2015). For further studies, it would be interesting to evaluate the variables of the present study in more critical situations such as the use of short implants $(<10 \mathrm{~mm})$, since short implants have lower survival rates compared to conventional implants (Lemos et al. 2016). Thus, the clinician could understand better the biomechanical risks in the use of pontic and cantilever.

Clinically, the appropriate occlusal adjustment reducing the occlusal table and the cusp inclination can contribute to better stress distribution (Verri et al. 2014), and to reduce the stress in the supporting structures, mainly when the appropriate number of implants may not be used. By this study, the ideal surgical/prosthetic planning in the posterior maxilla should be done with an implant for each missing tooth (M1) and in situations in which this is not possible should be considered as alternative treatments (M2, M3 and M4). Moreover, if the use of cantilevers (mesial or distal) are required, the clinicians should be aware of existing biomechanical risk, especially using distal cantilever or in patients with bruxism since this dysfunction can be prejudicial to the rehabilitation (Torcato et al. 2014).

The finite element analysis is considered a very useful tool for preclinical evaluation, especially to predict 
unfavorable situations (Limbert et al. 2010). However, this technique presents some limitations as well as other methodologies. In this study, the bone-implant-contact was considered full osseointegrated, as in previous studies (Torcato et al. 2014; Ramos Verri et al. 2015). However, this is not consistent with histologic studies (Caneva et al. 2015). In oblique loading, the values of microstrain were above of physiological limit of $3000 \mu \varepsilon$ suggested by Frost (2003). This fact could be interpreted as critical for osseointegration maintenance. However, bone tissue and other analyzed structures were considered isotropic, homogeneous, and linearly elastic as previous studies (Ramos Verri et al. 2015; Verri et al. 2016) which is not consistent with clinical reality despite biomechanical data of this study. Therefore, these results should be interpreted as unfavorable biomechanical conditions and the extrapolation to the daily clinic must be made with caution. Randomized controlled clinical trials should be performed for more reliable results that approximate to the clinical routine.

\section{Conclusion}

Within the limitation of this study and based on the methodology used, the following conclusions can be drawn:

(1) The use of one implant for each missed tooth provides lower values of stress/strain in all structures.

(2) In cases where is not possible one implant for each missing tooth, the use of cantilever (especially distal cantilever) should be avoided due to unfavorable biomechanical behavior, which could increase the chances of treatment failure.

\section{Disclosure statement}

No potential conflict of interest was reported by the authors.

\section{Funding}

This work was supported by Sao Paulo Research Foundation FAPESP, Brazil [grant number 2012/24893-1], [grant number 2012/24897-7]. Renato Archer Research Center, Campinas, Sao Paulo, Brazil. Conexao Sistemas de Protese, Aruja, Sao Paulo, Brazil.

\section{References}

Akca K, Iplikcioglu H. 2002. Finite element stress analysis of the effect of short implant usage in place of cantilever extensions in mandibular posterior edentulism. J Oral Rehabil. 29:350-356.

Alencar SM, Nogueira LB, Leal de Moura W, Rubo JH, de Oliveira Silva TS, Martins GA, Moura CD. 2015. FEA of peri-implant stresses in fixed partial denture prostheses with cantilevers. J Prosthodont. [Epub ahead of print]. doi: http://dx.doi.org/10.1111/jopr.12384

Caneva M, Lang NP, Calvo Guirado JL, Spriano S, Iezzi G, Botticelli D. 2015. Bone healing at bicortically installed implants with different surface configurations. An experimental study in rabbits. Clin Oral Implants Res. 26:293-299.

Chen XY, Zhang CY, Nie EM, Zhang MC. 2012. Treatment planning of implants when 3 mandibular posterior teeth are missing: a 3-dimensional finite element analysis. Implant Dent. 21:340-343.

Frost HM. 2003. Bone's mechanostat: a 2003 update. Anat Rec A Discov Mol Cell Evol Biol. 275A:1081-1101.

Fu JH, Hsu YT, Wang HL. 2012. Identifying occlusal overload and how to deal with it to avoid marginal bone loss around implants. Eur J Oral Implantol. 5(Suppl):S91-103.

Goiato MC, dos Santos DM, Santiago JF Jr, Moreno A, Pellizzer EP. 2014. Longevity of dental implants in type IV bone: a systematic review. Int J Oral Maxillofac Surg. 43:1108-1116.

Harder S, Wolfart S, Egert C, Kern M. 2011. Three-year clinical outcome of single implant-retained mandibular overdentures - Results of preliminary prospective study. J Dent. 39:656-661.

Hasan I, Bourauel C, Keilig L, Reimann S, Heinemann F. 2011. The influence of implant number and abutment design on the biomechanical behaviour of bone for an implantsupported fixed prosthesis: a finite element study in the upper anterior region. Comput Methods Biomech Biomed Eng. 14:1113-1116.

Kreissl ME, Gerds T, Muche R, Heydecke G, Strub JR. 2007. Technical complications of implant-supported fixed partial dentures in partially edentulous cases after an average observation period of 5 years. Clin Oral Implants Res. 18:720-726.

Lekholm U, Zarb G. 1985. Patient selection and preparation Tissue-integrated prostheses: osseointegration in clinical dentistry. Chicago (IL): Quintessence Inc.; p. 199-209.

Lemos CA, Ferro-Alves ML, Okamoto R, Mendonça MR, Pellizzer EP. 2016. Short dental implants versus standard dental implants placed in the posterior jaws: a systematic review and meta-analysis. J Dent. 47:8-17.

Limbert G, van Lierde C, Muraru OL, Walboomers XF, Frank M, Hansson S, Middleton J, Jaecques S. 2010. Trabecular bone strains around a dental implant and associated micromotions - A micro-CT-based three-dimensional finite element study. J Biomech. 43:1251-1261.

Milinkovic I, Cordaro L. 2014. Are there specific indications for the different alveolar bone augmentation procedures for implant placement? A systematic review. Int J Oral Maxillofac Surg. 43:606-625.

Pellizzer EP, de Mello CC, Santiago Junior JF, de Souza Batista VE, de Faria Almeida DA, Verri FR. 2015. Analysis of the biomechanical behavior of short implants: the photoelasticity method. Mater Sci Eng C Mater Biol Appl. 55:187192.

Pennington J, Parker S. 2012. Improving quality of life using removable and fixed implant prostheses. Compend Contin Educ Dent. 33:268-270, 272:274-266.

Puri N, Pradhan KL, Chandna A, Sehgal V, Gupta R. 2007. Biometric study of tooth size in normal, crowded, and spaced permanent dentitions. Am J Orthod Dentofacial Orthop. 132:279.e277-214. 
Ramos Verri F, Santiago Junior JF, de Faria Almeida DA, de Oliveira GB, de Souza Batista VE, Marques Honório H, Yoshito Noritomi PY, Piza Pellizzer EP. 2015. Biomechanical influence of crown-to-implant ratio on stress distribution over internal hexagon short implant: 3-D finite element analysis with statistical test. J Biomech. 48:138-145.

Sallam H, Kheiralla LS, Aldawakly A. 2012. Microstrains around standard and mini implants supporting different bridge designs. J Oral Implantol. 38:221-229.

Santiago JFJ, Verri FR, Almeida DA, de Souza Batista VE, Lemos CA, Pellizzer EP. 2016. Finite element analysis on influence of implant surface treatments, connection and bone types. Mater Sci Eng C Mater Biol Appl. 63:292-300.

Sevimay M, Turhan F, Kiliçarslan MA, Eskitascioglu G. 2005. Three-dimensional finite element analysis of the effect of different bone quality on stress distribution in an implantsupported crown. J Prosthet Dent. 93:227-234.

Torcato LB, Pellizzer EP, Verri FR, Falcón-Antenucci RM, Batista VE, Lopes LF. 2014. Effect of the parafunctional occlusal loading and crown height on stress distribution. Braz Dent J. 25:554-560.
Van Staden RC, Guan H, Loo YC. 2006. Application of the finite element method in dental implant research. Comput Methods Biomech Biomed Eng. 9:257-270.

Verri FR, Batista VE, Santiago JF Jr, Almeida DA, Pellizzer EP. 2014. Effect of crown-to-implant ratio on peri-implant stress: a finite element analysis. Mater Sci Eng C Mater Biol Appl. 45:234-240.

Verri FR, Cruz RS, de Souza Batista VE, Almeida DA, Verri AC, Lemos CA, Santiago Júnior JF, Pellizzer EP. 2016. Can the modeling for simplification of a dental implant surface affect the accuracy of 3D finite element analysis? Comput Methods Biomech Biomed Eng. 19:1665-1672.

Verri FR, Cruz RS, Lemos CA, de Souza Batista VE, Almeida DA, Verri AC, Pellizzer EP. 2017. Influence of bicortical techniques in internal connection placed in premaxillary area by $3 \mathrm{D}$ finite element analysis. Comput Methods Biomech Biomed Eng. 20:193-200.

Yokoyama S, Wakabayashi N, Shiota M, Ohyama T. 2004. The influence of implant location and length on stress distribution for three-unit implant-supported posterior cantilever fixed partial dentures. J Prosthet Dent. 91:234-240. 